\title{
Haar Wavelet Collocation Method for Solving Riccati and Fractional Riccati Differential Equations
}

\author{
S. C. Shiralashetti*, A. B. Deshi \\ Department of Mathematics, Karnatak University, Dharwad-580003, India \\ *shiralashettisc@gmail.com
}

\begin{abstract}
Keywords: Haar wavelet collocation method; Operational matrix; Riccati differential equations;
\end{abstract} Fractional Riccati differential equations; Resolution level.

\begin{abstract}
In this paper, numerical solutions of Riccati and fractional Riccati differential equations are obtained by the Haar wavelet collocation method. An operational matrix of integration based on the Haar wavelet is established, and the procedure for applying the matrix to solve these equations. The fundamental idea of Haar wavelet method is to convert the proposed differential equations into a group of non-linear algebraic equations. The accuracy of approximate solution can be further improved by increasing the level of resolution and an error analysis is computed. The examples are given to demonstrate the fast and flexibility of the method. The results obtained are in good agreement with the exact in comparison with existing ones and it is shown that the technique introduced here is robust, easy to apply and is not only enough accurate but also quite stable.
\end{abstract}

\section{Introduction}

Nonlinear phenomena occur in a wide variety of scientific applications such as plasma physics, solid state physics, fluid dynamics and chemical kinetics [2]. Riccati differential equations are a class of nonlinear differential equations of much importance, and play a significant role in many fields of applied science [21]. For instance, as well-known, a one-dimensional static Schrodinger equation is closely related to Riccati differential equation. Solitary wave solutions of a nonlinear partial differential equation can be expressed as a polynomial in two elementary functions satisfying a projective Riccati equation [8]. Because of the increased interest in the theory of solitary waves, a broad range of analytical and numerical methods have been used in the analysis of these scientific models. As a powerful mathematical tool, wavelet analysis has been widely used in image digital processing, quantum field theory, numerical analysis and many other fields in recent years. The Haar function, being an odd rectangular pulse pair, is one of the earliest examples of what is known now as a compact, dyadic, orthonormal wavelet transform. In the meantime, several definitions of the Haar functions and various generalizations have been published and used. They were intended to adopt this concept to some practical applications as well as to extend them to different classes of signals. Haar functions appear very attractive in many applications as for example, image coding, edge extraction, and binary logic design.

The previous work in system analysis via Haar wavelets was led by Chen and Hsiao [9], who first derived a Haar operational matrix for the integrals of the Haar function vector and put the applications for the Haar analysis into the dynamic systems. Lepik [17-18] presented solution for differential and integral by the Haar wavelet method. Bujurke et al. [5-7] used the Haar wavelet method to establish the solution of Nonlinear Oscillator Equations, Stiff systems, regular SturmLiouville problems etc. Dhawan et al. [10] applied the Haar wavelet scheme for the solution of differential equations. Siraj-ul-Islam et al. [15] presented numerical solution of second-order boundary-value problems by the Haar wavelets. Zhi Shi and Yongyan Cao [23] established the Haar wavelet method for solving higher order differential equations, Poisson equations and biharmonic equations on a rectangle. Some Ricctai differential equations with constant coefficients can be solved analytically by various methods [22]. Recently, Adomain's decomposition method (ADM) has been proposed for solving these equations in [12]. In addition, Abbasbandy [1] presented Homotopy perturbation method (HPM) for determining the solution of Riccati equations and the compared accuracy of the obtained solution with that derived by ADM. A novel and effective 
method for determining the approximate solution of these equations with constant and varying coefficients proposed in [24]. In [13] Modified variational iteration method (MVIM) presented to obtain a highly accurate numerical solution of Riccati equations.

The importance of Riccati fractional differential equation usually arises in the optimal control problems. The feedback gain of the linear quadratic optimal control depends on a solution of a Riccati differential equation which has to be found for the whole time horizon of the control process [3]. The existing literature on fractional differential equations tends to focus on particular values for the order $\alpha$. The value $\alpha=1 / 2$ is especially popular. This is because in classical fractional calculus, many of the model equations developed used these particular orders of derivatives [11]. In modern applications (see, e.g. [14]) much more general values of the order $\alpha$ appear in the equations and therefore one needs to consider numerical and analytical methods to solve differential equations of arbitrary order. Decomposition method is presented for solving fractional Riccati differential equations in [20].

In this paper, we establish a clear procedure for solving the proposed equations via HWCM; comparisons are made between HWCM and existing methods [13, 20, 24] with the exact solutions. The results reveal that the proposed method is very effective and simple and can be applied to other nonlinear problems.

The paper is divided as follows, Properties of Haar wavelets given in section 2. Section 3 deals with method of solution. Numerical findings with error analysis of test problems are presented in Section 4. Finally, concluding remarks of the proposed work are discussed in section 5.

\section{Properties of Haar wavelet}

\subsection{Haar wavelet}

The scaling function $h_{1}(x)$ for the family of the Haar wavelet is defined as

$$
h_{1}(x)=\left\{\begin{array}{lr}
1 & \text { for } x \in[0,1) \\
0 & \text { Otherwise }
\end{array}\right.
$$

The Haar wavelet family for $x \in[0,1)$ is defined as

$$
h_{i}(x)=\left\{\begin{array}{rc}
1 & \text { for } x \in\left[\frac{k}{m}, \frac{k+0.5}{m}\right) \\
-1 & \text { for } x \in\left[\frac{k+0.5}{m}, \frac{k+1}{m}\right) \\
0 & \text { Otherwise }
\end{array}\right.
$$

In the above definition the integer, $m=2^{l}, l=0,1, \ldots, J$, indicates the level of resolution of the wavelet and integer $k=0,1, \ldots, m-1$ is the translation parameter. Maximum level of resolution is $J$. The index $i$ in Eq. (2) is calculated using, $i=m+k+1$. In case of minimal values $m=1$, $k=0$, then $i=2$. The maximal value of $i$ is $K=2^{J+1}$.

Let us define the collocation points $x_{p}=\frac{p-0.5}{K}, p=1,2, \ldots, K$, discretize the Haar function $h_{i}(x)$ from Eq. (2), we get the Haar coefficient matrix $H(i, p)=\left(h_{i}\left(x_{p}\right)\right)$, which has the dimension $K \times K$.

Any function $f(x)$ which is square integrable in the interval $(0,1)$ can be expressed as an infinite sum of Haar wavelet as

$$
f(x)=\sum_{i=1}^{\infty} c_{i} h_{i}(x)
$$

The above series terminates at finite terms if $f(x)$ is piecewise constant or can be approximated as piecewise constant during each subinterval. Given a function $f(x) \in L_{2}(R)$ a multi-resolution analysis (MRA) of $L_{2}(R)$ produces a sequence of subspaces $V_{j}, V_{j+1}, \ldots$ such that the projections of $f(x)$ onto these spaces give finer and finer approximations of the function $f(x)$ as $j \rightarrow \infty$. 


\subsection{Operational matrices of the general order integration of the Haar wavelet}

The following notations are introduced

$$
\begin{gathered}
P H_{1, i}(x)=\int_{0}^{x} \mathrm{~h}_{i}(x) d x \\
P H_{n, i}(x)=\int_{0}^{x} P H_{n-1, i}(x) d x, \quad n=2,3, \ldots
\end{gathered}
$$

These integrals can be evaluated by using Eq. (2), first and $\mathrm{n}^{\text {th }}$ operational matrices are as follows,

$$
P H_{1, i}(x)=\left\{\begin{array}{cc}
x-\frac{k}{m} & \text { for } x \in\left[\frac{k}{m}, \frac{k+0.5}{m}\right) \\
\frac{k+1}{m}-x & \text { for } x \in\left[\frac{k+0.5}{m}, \frac{k+1}{m}\right) \\
0 & \text { Otherwise }
\end{array}\right.
$$

and

$$
P H_{n, i}(x)=\left\{\begin{array}{l}
\frac{1}{n !}\left(x-\frac{k}{m}\right)^{n} \\
\frac{1}{n !}\left\{\left(x-\frac{k}{m}\right)^{n}-2\left(x-\frac{k+0.5}{m}\right)^{n}\right\} \\
\frac{1}{n !}\left\{\left(x-\frac{k}{m}\right)^{n}-2\left(x-\frac{k+0.5}{m}\right)^{n}+\left(x-\frac{k+1}{m}\right)^{n}\right\} \\
0
\end{array}\right.
$$

$$
\begin{array}{r}
\text { for } x \in\left[\frac{k}{m}, \frac{k+0.5}{m}\right) \\
\text { for } x \in\left[\frac{k+0.5}{m}, \frac{k+1}{m}\right) \\
\text { for } x \in\left[\frac{k+1}{m}, 1\right)
\end{array}
$$

Otherwise

\subsection{Operational matrix of the fractional order integration of the Haar wavelet}

We introduce the Haar wavelet operational matrix $F H_{\alpha}$ of integration of the fractional order $\alpha$ is given by

$$
F H_{\alpha, i}(x)=\left\{\begin{array}{lr}
f_{1} & \text { for } x \in\left[\frac{k}{m}, \frac{k+0.5}{m}\right) \\
f_{2} & \text { for } x \in\left[\frac{k+0.5}{m}, \frac{k+1}{m}\right) \\
f_{3} & \text { for } x \in\left[\frac{k+1}{m}, 1\right) \\
0 & \text { Otherwise }
\end{array}\right.
$$

where

$$
\begin{aligned}
& f_{1}=\frac{1}{\Gamma(\alpha+1)}\left(x-\frac{k}{m}\right)^{\alpha} \\
& f_{2}=\frac{1}{\Gamma(\alpha+1)}\left\{\left(x-\frac{k}{m}\right)^{\alpha}-2\left(x-\frac{k+0.5}{m}\right)^{\alpha}\right\} \\
& f_{3}=\frac{1}{\Gamma(\alpha+1)}\left\{\left(x-\frac{k}{m}\right)^{\alpha}-2\left(x-\frac{k+0.5}{m}\right)^{\alpha}+\left(x-\frac{k+1}{m}\right)^{\alpha}\right\}
\end{aligned}
$$

It is necessary to evaluate these functions for a prescribed $J$ only once, save them in the computer and is convenient to pass the matrix formulation. The integral matrices $P H_{1}$ and $F H_{\alpha}$ can be calculated from the Eqs. (5) and (7) respectively.

\section{Method of solution}

\subsection{First order Riccati differential equations}

Consider the general Riccati differential equation,

$$
\left\{\begin{array}{l}
y^{\prime}(t)+f(t) y^{2}(t)+g(t) y(t)+h(t)=0,0 \leq t \leq a, f(t) \neq 0 \\
y(0)=\beta
\end{array}\right.
$$


Substituting $t=a x$ in (8) which reduces to

$$
\left\{\begin{array}{l}
y^{\prime}(x)+a f(x) y^{2}(x)+a g(x) y(x)+a h(x)=0,0 \leq x \leq 1, f(x) \neq 0 \\
y(0)=\beta
\end{array}\right.
$$

We assume that

$$
y^{\prime}(x)=\sum_{i=1}^{K} \mathrm{c}_{\mathrm{i}} \mathrm{h}_{i}(x)
$$

where $c_{i}$ 's are Haar coefficients to be determined. Integrating (10) with respect to $x$, we get

$$
y(x)=\beta+\sum_{i=1}^{K} \mathrm{c}_{\mathrm{i}} \mathrm{P}_{1, i}(x)
$$

Substituting (10) and (11) in (9), we get

$$
\sum_{i=1}^{K} \mathrm{c}_{\mathrm{i}} \mathrm{h}_{i}(x)+a f(x)\left(\beta+\sum_{i=1}^{K} \mathrm{c}_{\mathrm{i}} \mathrm{P}_{1, i}(x)\right)^{2}+a g(x)\left(\beta+\sum_{i=1}^{K} \mathrm{c}_{\mathrm{i}} \mathrm{P}_{1, i}(x)\right)+a h(x)=0
$$

Solving (12) to calculate Haar coefficients $c_{i}$ 's using MatLab. Substituting these $c_{i}$ 's in (11), to obtain the numerical solution $y(x)$ of (9), finally obtained the solution $y(t)$ of $(8)$.

\subsection{Fractional order Riccati differential equations}

Consider the general fractional order Riccati differential equation,

$$
\mathrm{y}^{\alpha}(\mathrm{t})=\mathrm{A}(\mathrm{t})+\mathrm{B}(\mathrm{t}) \mathrm{y}(\mathrm{t})+\mathrm{C}(\mathrm{t}) \mathrm{y}^{2}(\mathrm{t}), \quad 0 \leq \mathrm{t} \leq \mathrm{a}, \mathrm{n}-1<\alpha<\mathrm{n}
$$

subject to initial conditions $y^{(j)}(0)=a_{j}, j=0,1, \ldots, n-1$,

where $n$ is Natuarl number, $A(t), B(t)$ and $C(t)$ are given functions, $a_{j}$ 's are arbitrary constants and $\alpha$ is a parameter describing the order of the fractional derivative. The general response expression contains a parameter describing the order of the fractional derivative that can be varied to obtain various responses. In the case of $\alpha=1$, the fractional equation reduces to the classical Riccati differential equation.

Substituting $\mathrm{t}=$ ax in (13) which reduces to

$$
y^{\alpha}(x)=a A(x)+a B(x) y(x)+a C(x) y^{2}(x), \quad 0 \leq x \leq 1
$$

We assume that

$$
\mathrm{y}^{\alpha}(\mathrm{x})=\sum_{\mathrm{i}=1}^{\mathrm{K}} \mathrm{c}_{\mathrm{i}} \mathrm{h}_{\mathrm{i}}(\mathrm{x}) .
$$

If $\alpha=1 / 2$, integrating (15) once, we get

$$
\mathrm{y}(\mathrm{x})=\mathrm{a}_{0}+\sum_{\mathrm{i}=1}^{\mathrm{K}} \mathrm{c}_{\mathrm{i}} \mathrm{FH}_{1 / 2, \mathrm{i}}(\mathrm{x}) .
$$

Substituting (15) and (16) in (14), we get

$$
\begin{aligned}
\sum_{\mathrm{i}=1}^{\mathrm{K}} \mathrm{c}_{\mathrm{i}} \mathrm{h}_{\mathrm{i}}(\mathrm{x})-\mathrm{aA}(\mathrm{x})-\mathrm{aB}(\mathrm{x})\left(\mathrm{a}_{0}+\sum_{\mathrm{i}=1}^{\mathrm{K}} \mathrm{c}_{\mathrm{i}} \mathrm{FH}_{1 / 2, \mathrm{i}}(\mathrm{x})\right) \\
\quad-\mathrm{aC}(\mathrm{x})\left(\mathrm{a}_{0}+\sum_{\mathrm{i}=1}^{\mathrm{K}} \mathrm{c}_{\mathrm{i}} \mathrm{FH}_{1 / 2, \mathrm{i}}(\mathrm{x})\right)^{2}=0
\end{aligned}
$$

If $\alpha=3 / 2$, integrating (15) twice, we get

$$
\begin{gathered}
y^{1 / 2}(x)=a_{1}+\sum_{i=1}^{K} c_{i} F_{1 / 2}, i(x) \\
y(x)=a_{0}+a_{1} x+\sum_{i=1}^{K} c_{i} F_{3 / 2}, i(x)
\end{gathered}
$$

Substituting (15) and (19) in (14), we get

$$
\begin{gathered}
\sum_{i=1}^{\mathrm{K}} \mathrm{c}_{\mathrm{i}} \mathrm{h}_{\mathrm{i}}(\mathrm{x})-\mathrm{aA}(\mathrm{x})-\mathrm{aB}(\mathrm{x})\left(\mathrm{a}_{0}+\mathrm{a}_{1} \mathrm{x}+\sum_{\mathrm{i}=1}^{\mathrm{K}} \mathrm{c}_{\mathrm{i}} \mathrm{FH}_{3 / 2, \mathrm{i}}(\mathrm{x})\right)- \\
\mathrm{aC}(\mathrm{x})\left(\mathrm{a}_{0}+\mathrm{a}_{1} \mathrm{x}+\sum_{\mathrm{i}=1}^{\mathrm{K}} \mathrm{c}_{\mathrm{i}} \mathrm{FH}_{3 / 2}, \mathrm{i}(\mathrm{x})\right)^{2}=0
\end{gathered}
$$


Solving (17), in case of $\alpha=1 / 2$ or (20) in case of $\alpha=3 / 2$, using MatLab to calculate Haar coefficients $c_{i}$ 's. Substituting $c_{i}$ 's in (16) in case of $\alpha=1 / 2$ or in (19) in case of $\alpha=3 / 2$ to obtain $y(x)$, finally, obtained the HWCM solution $y(t)$ of (13).

The accuracy of the HWCM for the solution of the proposed problems is assessed in terms of the following error norms.

$$
\begin{gathered}
\mathrm{L}_{\infty}=\operatorname{Max}\left|\mathrm{y}_{\mathrm{p}}^{\mathrm{e}}-\mathrm{y}_{\mathrm{p}}^{\mathrm{a}}\right| \\
\text { Maximum Relative Error }=\mathrm{L}_{\mathrm{mre}}=\frac{\mathrm{L}_{\infty}}{\left|\mathrm{y}_{\mathrm{p}}^{\mathrm{e}}\right|} \\
\text { Relative Power Deviations }(\%)=\mathrm{L}_{\mathrm{rpd}}=\sum_{\mathrm{p}=1}^{\mathrm{K}} \frac{\left|\mathrm{y}_{\mathrm{p}}^{\mathrm{e}}-\mathrm{y}_{\mathrm{p}}^{\mathrm{a}}\right|^{2}}{\left|\mathrm{y}_{\mathrm{p}}^{\mathrm{e}}\right|^{2}} \times 100
\end{gathered}
$$

where $y_{p}^{e}$ and $y_{p}^{a}$ are the exact and approximate solution respectively at the $\mathrm{p}^{\text {th }}$ collocation point.

\section{Numerical examples}

The HWCM provides a reliable technique that requires less computational cost as compared with traditional techniques for the solution of Riccati and Fractional Riccati differential equations. To give a clear overview of the methodology, the following examples will be discussed. All the results are calculated by using MatLab.

Example 1. First, consider the Riccati differential equation [24],

$$
\left\{\begin{array}{l}
y^{\prime}(t)+y^{2}(t)-2 y(t)-1=0,0 \leq t \leq 4 \\
y(0)=0
\end{array}\right.
$$

Substituting $\mathrm{t}=4 \mathrm{x}$ in (24) which reduces to

$$
\left\{\begin{array}{l}
y^{\prime}(x)+4 y^{2}(x)-8 y(x)-4=0, \quad 0 \leq x \leq 1 \\
y(0)=0
\end{array}\right.
$$

We assume

$$
\mathrm{y}^{\prime}(\mathrm{x})=\sum_{\mathrm{i}=1}^{\mathrm{K}} \mathrm{c}_{\mathrm{i}} \mathrm{h}_{\mathrm{i}}(\mathrm{x})
$$

Integrating (26) with respect to $x$, we get

$$
\mathrm{y}(\mathrm{x})=\sum_{\mathrm{i}=1}^{\mathrm{K}} \mathrm{c}_{\mathrm{i}} \mathrm{P}_{1, \mathrm{i}}(\mathrm{x})
$$

Substituting (26) and (27) in (25), we get

$$
\sum_{\mathrm{i}=1}^{\mathrm{K}} \mathrm{c}_{\mathrm{i}} \mathrm{h}_{\mathrm{i}}(\mathrm{x})+4\left(\sum_{\mathrm{i}=1}^{\mathrm{K}} \mathrm{c}_{\mathrm{i}} \mathrm{P}_{1, \mathrm{i}}(\mathrm{x})\right)^{2}-8\left(\sum_{\mathrm{i}=1}^{\mathrm{K}} \mathrm{c}_{\mathrm{i}} \mathrm{P}_{1, \mathrm{i}}(\mathrm{x})\right)-4=0
$$

Solving (28), we get the Haar wavelet coefficients $c_{\mathrm{i}}$ 's $\mathrm{s}=[2.41,2.32,2.12,0.09,-0.66,1.38,0.12$, $0.01,-1.00,0.49,0.99,0.40,0.10,0.02,0.01,0.00]$. Substituting $\mathrm{c}_{\mathrm{i}}$ 's in (27), we obtained the HWCM solution $y(t)$ of (24) and is presented in in Fig. 1 for $\mathrm{K}=32$, in comparison with the existing method [24] with the exact solution

$$
y(t)=1+\sqrt{2} \tanh \left(\sqrt{2} t+\frac{\log \left(\frac{-1+\sqrt{2}}{1+\sqrt{2}}\right)}{2}\right)
$$

Error graph is given in Fig. 2 for $\mathrm{K}=16$. The error analysis of the example 1 for higher values of $\mathrm{K}$ is given in table 1 .

Example 2. Next consider the Riccati differential equation [24],

$$
\left\{\begin{array}{l}
y^{\prime}(t)-y^{2}(t)-1=0, \quad 0 \leq t \leq 1.5 \\
y(0)=0
\end{array}\right.
$$


Using the procedure explained in section 3.1, we obtained the Haar wavelet coefficients $\mathrm{c}_{\mathrm{i}}$ 's $=$ $[15.92,-14.06,-0.29,-25.32,-0.06,-0.26,-1.21,-41.63,-0.01,-0.04,-0.09,-0.17,-0.36,-0.92$, $-3.54,-59.99,-0.00,-0.01,-0.02,-0.03,-0.04,-0.05,-0.07,-0.10,-0.15,-0.22,-0.35,-0.60,-1.14$, $-2.60,-8.36,-72.67]$. Using these coefficients, obtained the HWCM solution $\mathrm{y}(\mathrm{t})$, is presented in Fig. 3 for $K=64$ with the existing method [24] and exact solution

$$
y(t)=\tan (t)
$$

Error graph is given in Fig. 4 for $\mathrm{K}=32$. The error analysis of the example 2 for higher values of $\mathrm{K}$ is given in table 2 .

Example 3. Now, consider Riccati differential equation [24],

$$
\left\{\begin{array}{l}
y^{\prime}(t)+y^{2}(t)-t^{2}-1=0, \quad 0 \leq t \leq 4 \\
y(0)=0
\end{array}\right.
$$

Obtained Haar wavelet coefficients of (32) are $c_{i}$ 's $=[3.00,-0.98,-1.19,-0.02,-0.58,-0.43,-0.03$, $-0.00,-0.19,-0.36,-0.30,-0.13,-0.03,-0.00,-0.00,-0.00]$. Using these coefficients, we obtained the HWCM solution is presented in Fig. 5 for $\mathrm{K}=32$, and is compared with the existing method with the exact solution

$$
y(t)=t+\frac{\exp \left(-t^{2}\right)}{1+\int_{0}^{t} \exp \left(-x^{2}\right) d x}
$$

Error graph is given in Fig. 6 for $\mathrm{K}=32$. The error analysis of the example 3 for higher values of $\mathrm{K}$ is given in table 3 .

Example 4. Now consider fractional order Riccati differential equation [20],

$$
\left\{\begin{array}{l}
\mathrm{y}^{(1 / 2)}(\mathrm{t})+\mathrm{y}^{2}(\mathrm{t})-1=0,0 \leq \mathrm{t} \leq 6 \\
\mathrm{y}(0)=0
\end{array}\right.
$$

Using the Procedure explained in section 3.2, obtained the Haar wavelet coefficients of (34), $\mathrm{c}_{\mathrm{i}}{ }^{\prime} \mathrm{s}=[1.04,0.38,0.50,0.06,0.63,0.08,0.04,0.02,0.79,0.11,0.05,0.03,0.02,0.02,0.01,0.01]$. Using these coefficients, we get the HWCM solution $y(t)$ of (34), is presented in Fig. 7 (a) and Fig. 7 (b) for $\mathrm{K}=32$ and compared it with the existing method [20] and exact solution

$$
y(t)=\frac{\exp \left(2 t^{1 / 2}\right)-1}{\exp \left(2 t^{1 / 2}\right)+1}
$$

Error graph is given in Fig. 8 (a) and Fig. 8 (b) for $K=32$. The error analysis of the example 4 for higher values of $\mathrm{K}$ is given in table 4 .

Example 5. Finally, consider another fractional order Riccati differential equation [20],

$$
\left\{\begin{array}{l}
\mathrm{y}^{(3 / 2)}(\mathrm{t})+\mathrm{y}^{2}(\mathrm{t})-1=0,0 \leq \mathrm{t} \leq 10 \\
\mathrm{y}(0)=\sqrt{2}, \mathrm{y}^{\prime}(0)=-1
\end{array}\right.
$$

Obtained Haar wavelet coefficients of (36), $\mathrm{c}_{\mathrm{i}}$ 's $=[0.90,0.04,-1.21,0.11,0.85,1.26,0.09,0.04$, $-44.58,6.47,0.99,-0.35,0.13,0.02,0.02,0.02]$. Using these $c_{i}$ 's, we obtained the HWCM solution of (36) is presented in Fig. 9 (a) and Fig. 9 (b) for $\mathrm{K}=32$, and is compared it with the existing method and exact solution

$$
y(t)=\frac{\exp \left(2 t^{3 / 2}\right)-1}{\exp \left(2 t^{3 / 2}\right)+1}
$$

Error graph is given in Fig. 10 (a) and Fig. 10 (b) for $\mathrm{K}=32$. The error analysis of the example 5 for higher values of $\mathrm{K}$ is given in table 5 . 


\section{Conclusions}

In this study, Haar wavelet collocation method is successfully applied to obtain numerical solutions of Riccati and fractional Riccati differential equations. Although, the learned researchers Chen and Hsiao [9], Kilicman and Zhour [16], Li and Zhao [19] and Bouafoura and Braiek [4] proposed the generalized operational matrix of integration which is an approximate matrix in nature. But it is not the exact generalized operational matrix. Moreover, it has drawback for obtaining the correct integer order operational matrices from the generalized operational matrix. In the present analysis, the presented Haar wavelet operational matrix $\mathrm{PH}_{\mathrm{n}, \mathrm{i}}(\mathrm{x})$ and $\mathrm{FH}_{\alpha, \mathrm{i}}(\mathrm{x})$ of integration of the general order $\mathrm{n}$ and $\alpha$ is the correct operational matrix respectively. The above examples justify its correctness. The main advantage of this method is its simplicity and less computation costs: it is due to the sparcity of the transform matrices and to the small number of significant wavelet coefficients. We have achieved a very good agreement between the approximate solution obtained by existing methods $[24,13,20]$. The results show that HWCM is reliable and efficient method for solving these problems.

\section{Acknowledgement}

The authors thank the UGC, New Delhi for the financial support of UGC's Research Fellowship in Science for Meritorious Students vide sanction letter No. F. 4-1/2006(BSR)/7-101/2007(BSR), dated-02/01/2013.

Table 1. Error analysis of the example 1.

\begin{tabular}{ccccc}
\hline $\mathrm{K}$ & $\mathrm{L}_{\infty}(\mathrm{HWCM})$ & $\mathrm{L}_{\text {mre }}(\mathrm{HWCM})$ & $\mathrm{L}_{\mathrm{rpd}}(\mathrm{HWCM})$ & $\mathrm{L}_{\infty}(\mathrm{ASM})$ \\
\hline 8 & $9.8287 \mathrm{E}-02$ & $3.1110 \mathrm{E}-01$ & $5.5114 \mathrm{E}-03$ & $4.7936 \mathrm{E}-01$ \\
16 & $2.6161 \mathrm{E}-02$ & $1.8530 \mathrm{E}-01$ & $3.8907 \mathrm{E}-04$ & $5.6267 \mathrm{E}-01$ \\
32 & $6.4926 \mathrm{E}-03$ & $9.7659 \mathrm{E}-02$ & $2.4825 \mathrm{E}-05$ & $6.0545 \mathrm{E}-01$ \\
64 & $1.6454 \mathrm{E}-03$ & $5.1043 \mathrm{E}-02$ & $1.5592 \mathrm{E}-06$ & $6.2714 \mathrm{E}-01$ \\
128 & $4.1258 \mathrm{E}-04$ & $2.5997 \mathrm{E}-02$ & $9.7570 \mathrm{E}-08$ & $6.3807 \mathrm{E}-01$ \\
\hline
\end{tabular}

Table 2. Error analysis of the example 2.

\begin{tabular}{ccccc}
\hline $\mathrm{K}$ & $\mathrm{L}_{\infty}(\mathrm{HWCM})$ & $\mathrm{L}_{\mathrm{mre}}(\mathrm{HWCM})$ & $\mathrm{L}_{\mathrm{rpd}}(\mathrm{HWCM})$ & $\mathrm{L}_{\infty}(\mathrm{ASM})$ \\
\hline 32 & 1.7507 & 74.6837 & 2.1441 & 3.4346 \\
64 & 0.4957 & 42.2983 & 0.1105 & 4.8652 \\
128 & 0.1447 & 24.6882 & 0.0069 & 5.9237 \\
256 & 0.0400 & 13.6419 & $4.2927 \mathrm{E}-04$ & 6.5830 \\
\hline
\end{tabular}

Table 3. Error analysis of the example 3.

\begin{tabular}{ccccc}
\hline $\mathrm{K}$ & $\mathrm{L}_{\infty}(\mathrm{HWCM})$ & $\mathrm{L}_{\text {mre }}(\mathrm{HWCM})$ & $\mathrm{L}_{\mathrm{rpd}}(\mathrm{HWCM})$ & $\mathrm{L}_{\infty}(\mathrm{FDM})$ \\
\hline 8 & $6.2435 \mathrm{E}-03$ & $6.2148 \mathrm{E}-03$ & $3.6537 \mathrm{E}-05$ & $2.8796 \mathrm{E}-02$ \\
16 & $1.8249 \mathrm{E}-03$ & $1.8238 \mathrm{E}-03$ & $2.0847 \mathrm{E}-06$ & $1.5404 \mathrm{E}-02$ \\
32 & $4.6692 \mathrm{E}-04$ & $4.6688 \mathrm{E}-04$ & $1.2786 \mathrm{E}-07$ & $7.9011 \mathrm{E}-03$ \\
64 & $1.1677 \mathrm{E}-04$ & $1.1677 \mathrm{E}-04$ & $7.9563 \mathrm{E}-09$ & $4.0032 \mathrm{E}-03$ \\
128 & $2.9198 \mathrm{E}-05$ & $2.9198 \mathrm{E}-05$ & $4.9673 \mathrm{E}-10$ & $2.0153 \mathrm{E}-03$ \\
\hline
\end{tabular}

Table 4. Error analysis of the example 4.

\begin{tabular}{cccccc}
\hline $\mathrm{K}$ & $\mathrm{L}_{\infty}(\mathrm{HWCM})$ & $\mathrm{L}_{\text {mre }}(\mathrm{HWCM})$ & $\mathrm{L}_{\text {rpd }}(\mathrm{HWCM})$ & $\mathrm{L}_{\infty}(\mathrm{ADM})$ & $\mathrm{L}_{\infty}$ (Pade Appr. $)$ \\
\hline 8 & $2.0151 \mathrm{E}-01$ & $3.6921 \mathrm{E}-01$ & $4.2416 \mathrm{E}-01$ & $3.1029 \mathrm{E}+12$ & $3.0273 \mathrm{E}-01$ \\
16 & $2.5815 \mathrm{E}-01$ & $6.3297 \mathrm{E}-01$ & $4.5504 \mathrm{E}-01$ & $4.3858 \mathrm{E}+12$ & $2.9453 \mathrm{E}-01$ \\
32 & $2.8101 \mathrm{E}-01$ & $9.4628 \mathrm{E}-01$ & $4.6430 \mathrm{E}-01$ & $5.1925 \mathrm{E}+12$ & $3.0078 \mathrm{E}-01$ \\
64 & $3.1279 \mathrm{E}-01$ & 1.4672 & $4.6769 \mathrm{E}-01$ & $5.6442 \mathrm{E}+12$ & $3.0264 \mathrm{E}-01$ \\
128 & $3.1524 \mathrm{E}-01$ & 2.0752 & $4.6882 \mathrm{E}-01$ & $5.8831 \mathrm{E}+12$ & $3.0286 \mathrm{E}-01$ \\
\hline
\end{tabular}


Table 5. Error analysis of the example 5.

\begin{tabular}{cccccc}
\hline $\mathrm{K}$ & $\mathrm{L}_{\infty}(\mathrm{HWCM})$ & $\mathrm{L}_{\text {mre }}(\mathrm{HWCM})$ & $\mathrm{L}_{\mathrm{rpd}}(\mathrm{HWCM})$ & $\mathrm{L}_{\infty}(\mathrm{ADM})$ & $\mathrm{L}_{\infty}$ (Pade Appr. $)$ \\
\hline 8 & 1.9275 & 4.2135 & 76.2068 & $1.5310 \mathrm{E}+02$ & 0.5953 \\
16 & 1.0271 & 5.9392 & 0.2436 & $1.5867 \mathrm{E}+02$ & 0.8729 \\
32 & 1.2362 & 20.0421 & 0.2461 & $1.6116 \mathrm{E}+02$ & 1.1647 \\
64 & 1.3401 & 61.3816 & 0.2575 & $1.6232 \mathrm{E}+02$ & 1.3007 \\
128 & 1.3853 & $1.7943 \mathrm{E}+02$ & 0.2596 & $1.6288 \mathrm{E}+02$ & 1.3621 \\
\hline
\end{tabular}

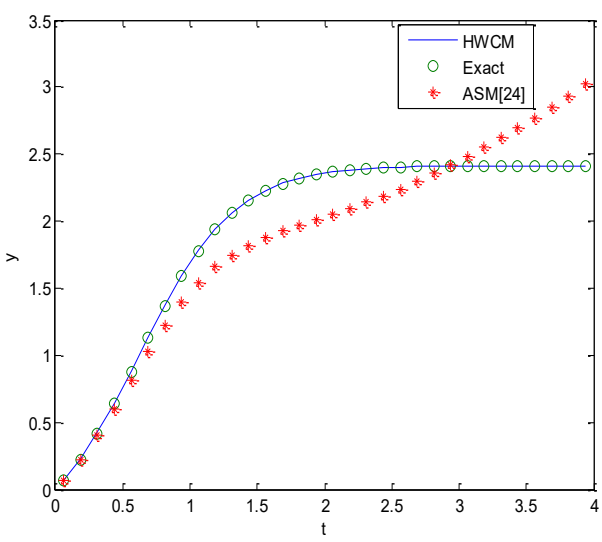

Fig. 1. Comparison of numerical solutions with exact solution of example 1 for $\mathrm{K}=32$.

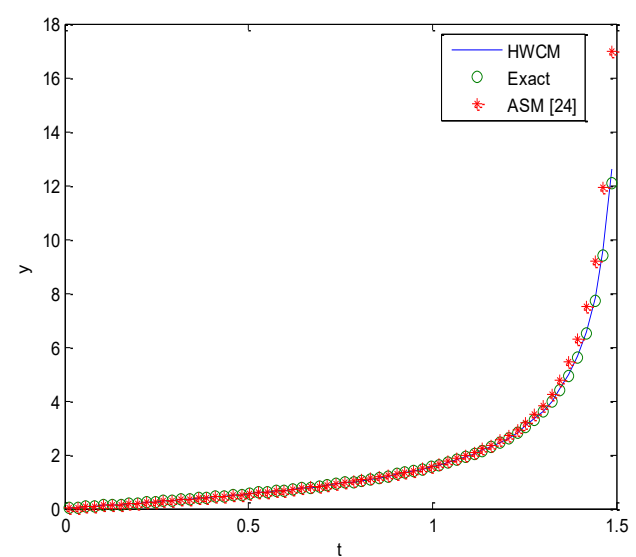

Fig. 3. Comparison of numerical solutions with exact solution of example 2 for $\mathrm{K}=64$.

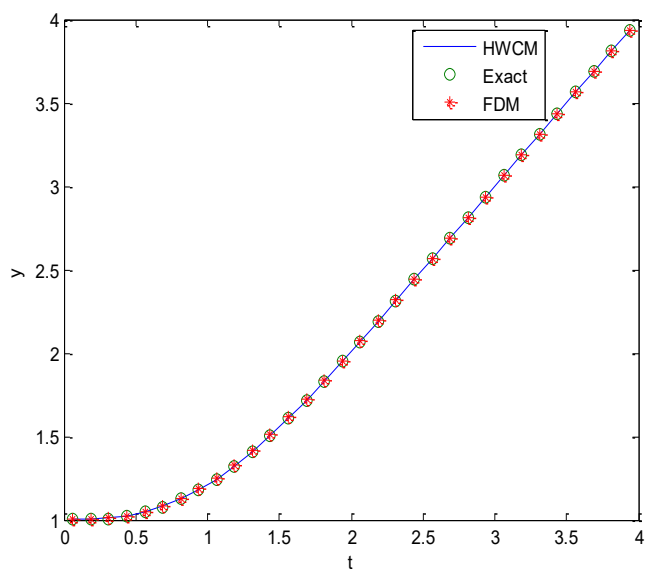

Fig. 5. Comparison of numerical solutions with exact solution of Example 3 for $\mathrm{K}=32$.

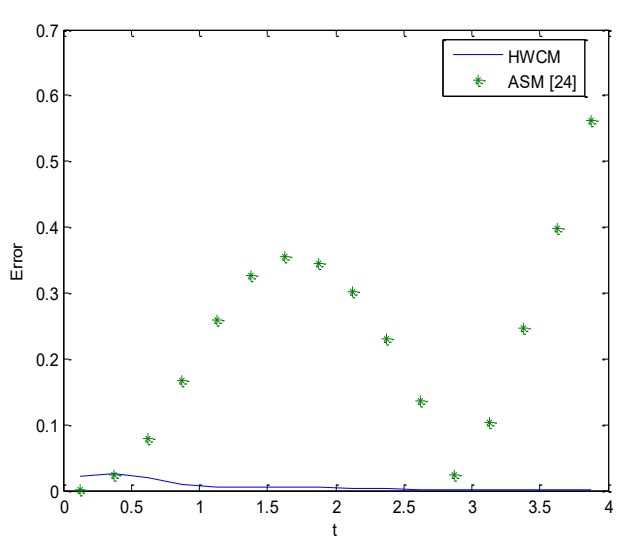

Fig. 2. Comparison errors of HWCM and approximate solution method (ASM) [24] of example 1 for $\mathrm{K}=16$.

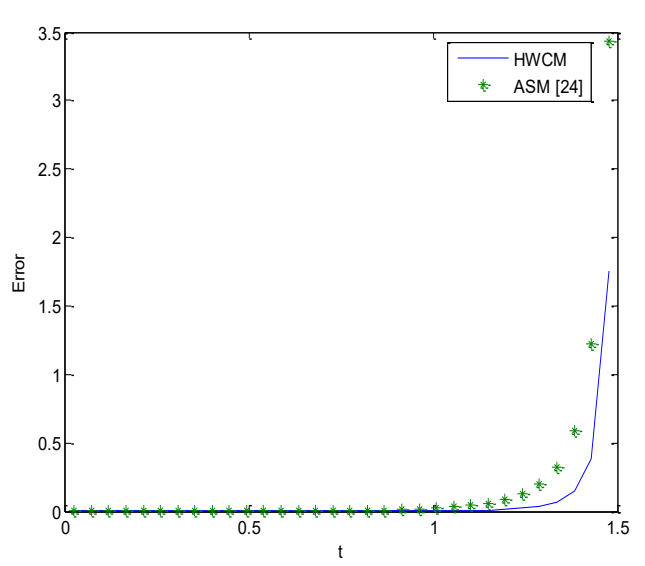

Fig. 4. Comparison of errors of HWCM and approximate solution method (ASM) [24] of example 2 for $\mathrm{K}=32$.

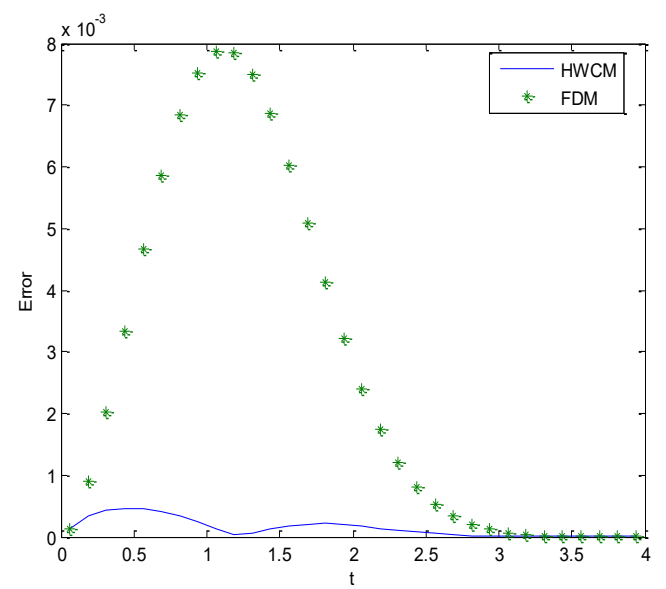

Fig. 6. Comparison of errors of HWCM and FDM of Example 3 for $\mathrm{K}=32$. 


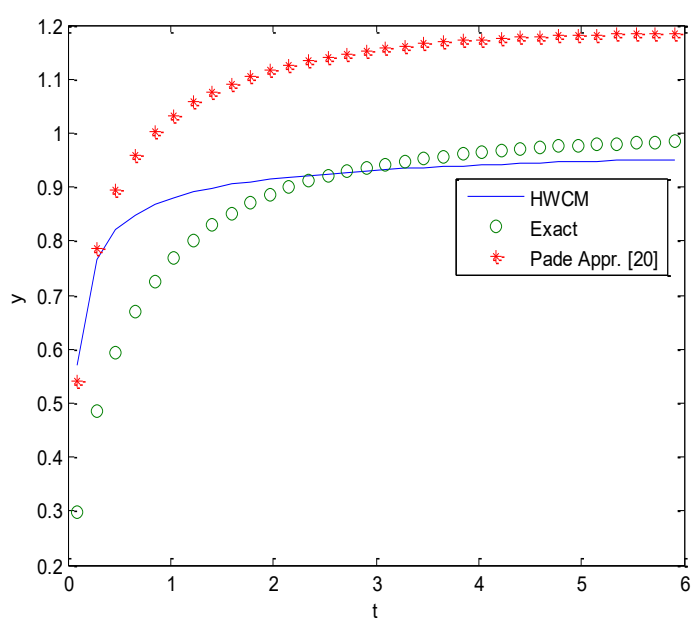

(a)

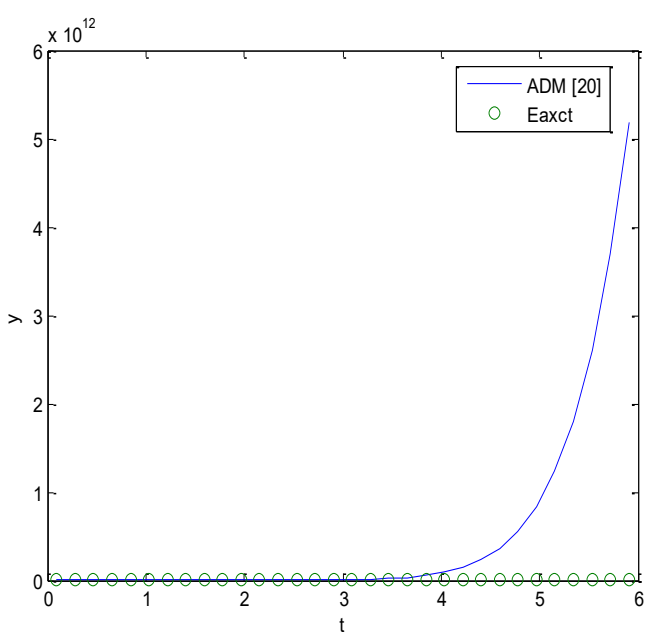

(b)

Fig. 7. (a) Comparison of numerical solutions with solution of example 4 for $\mathrm{K}=32$;

(b) Comparison of ADM solution with exact solution of example 4 for $\mathrm{K}=32$.

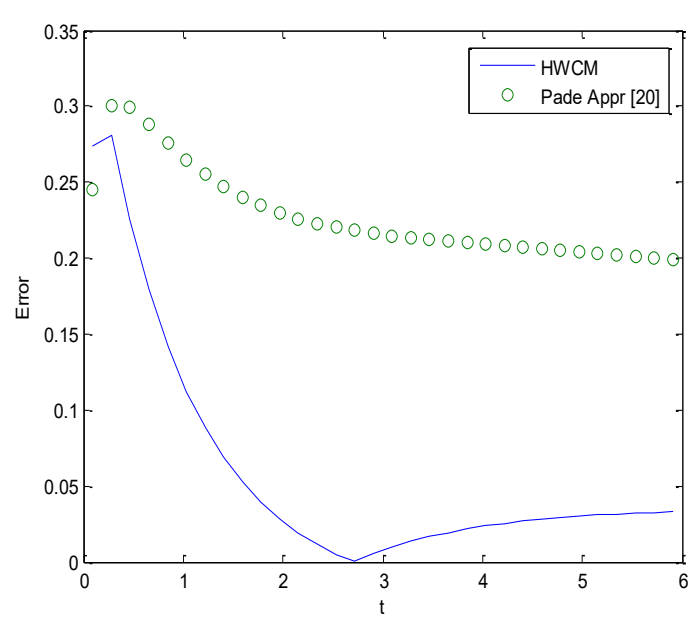

(a)

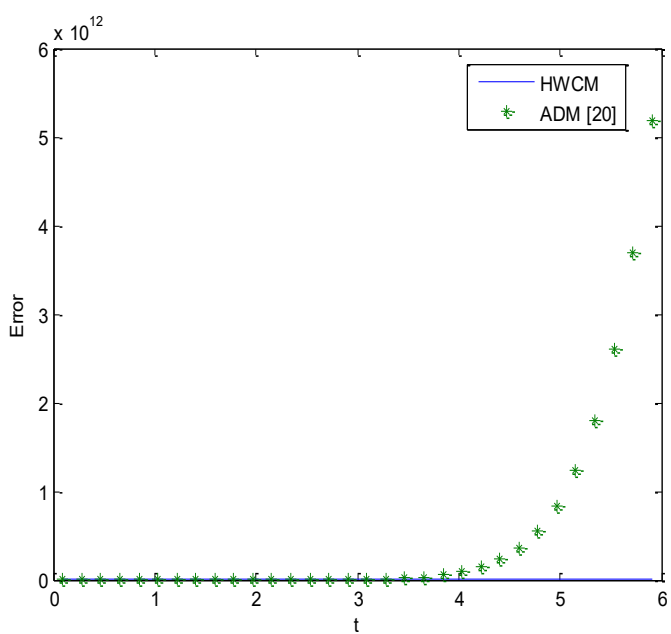

(b)

Fig. 8. (a) Comparison of errors of HWCM and Pade Appr of example 4 for $\mathrm{K}=32$; (b) Comparison of errors of HWCM and ADM of example 4 for $\mathrm{K}=32$.

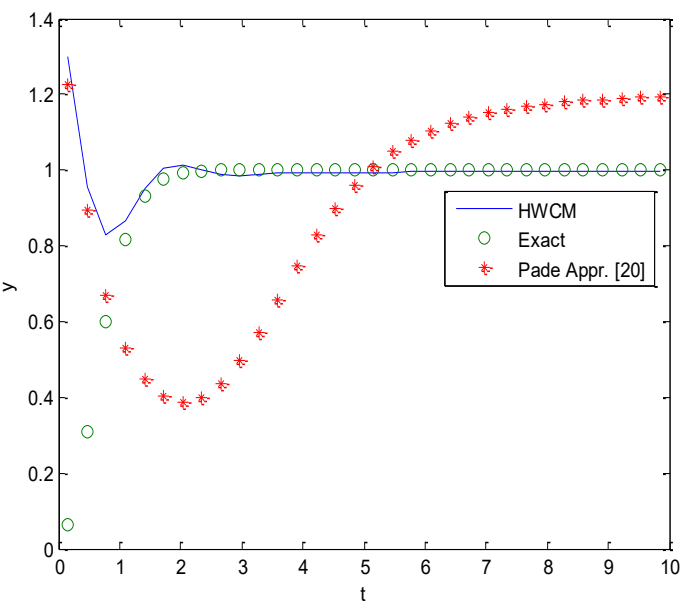

(a)

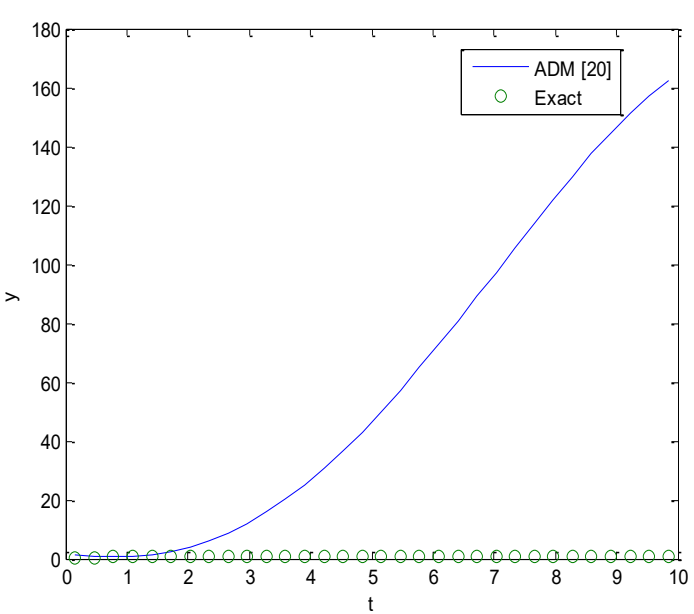

(b)

Fig. 9. (a) Comparison of numerical solutions with solution of example 5 for $\mathrm{K}=32$;

(b) Comparison of ADM solution with exact solution of example 5 for $\mathrm{K}=32$. 


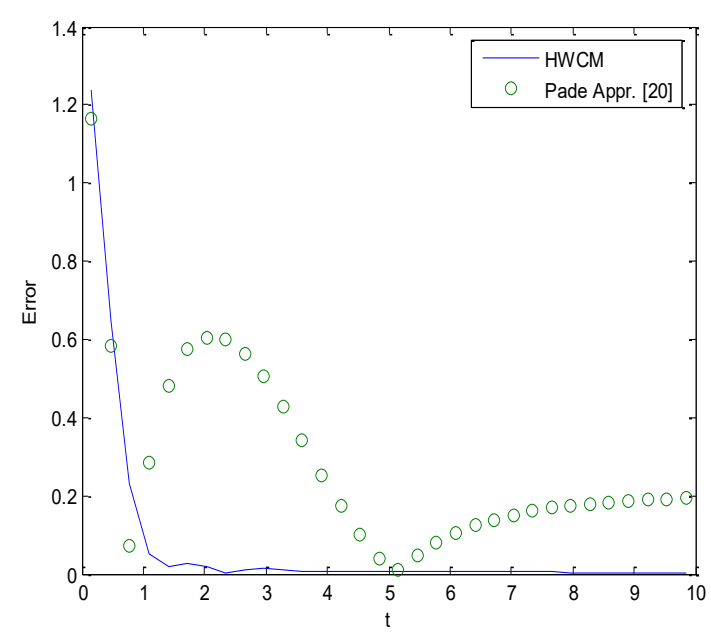

(a)

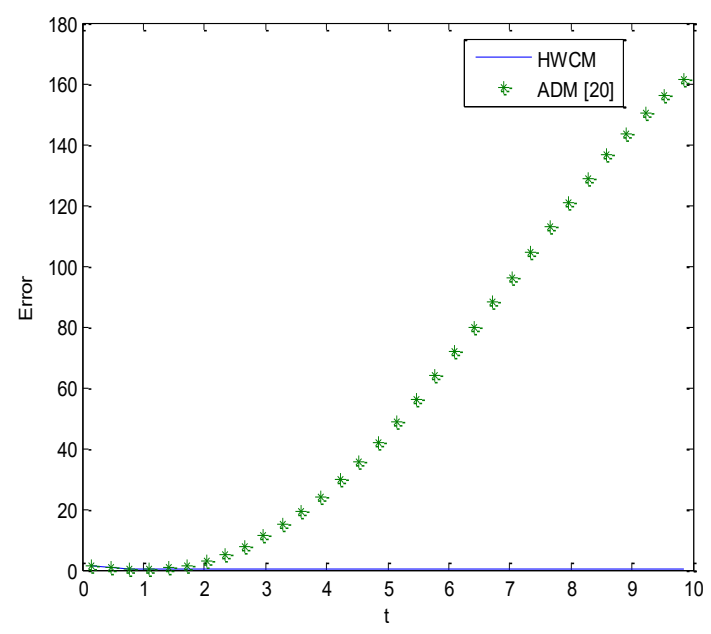

(b)

Fig. 10. (a) Comparison of numerical solutions with solution of example 5 for $K=32$;

(b) Comparison of ADM solution with exact solution of example 5 for $\mathrm{K}=32$.

\section{References}

[1] S. Abbasbandy, Homotopy perturbation method for quadratic Riccati differential equation and comparison with Adomians decomposition method, Appl. Math. Comput. 172 (2006) 485490.

[2] M.J. Ablowitz, P.A. Clarkson, Solitons, Nonlinear Evolution Equations and Inverse Scattering Transform, Cambridge University Press, Cambridge, 1990.

[3] B.D. Anderson, J.B. Moore, Optimal Control-Linear Quadratic Methods, Prentice-Hall, New Jersey, 1990.

[4] M.K. Bouafoura, N.B. Braiek, $P I^{\lambda} D^{\mu}$ controller design for integer and fractional plants using piecewise orthogonal functions, Commun. Nonlinear Sci. Numer. Simul. 15 (2010) 12671278.

[5] N.M. Bujurke, C.S Salimath, S.C. Shiralashetti, Numerical Solution of Stiff Systems from Nonlinear Dynamics Using Single-term Haar Wavelet Series, Nonlinear Dyn. 51 (2008) 595605.

[6] N.M. Bujurke, C.S. Salimath, S.C. Shiralashetti, Computation of eigenvalues and solutions of regular Sturm-Liouville problems using Haar wavelets, J. Comp. Appl. Math. 219 (2008) 90101.

[7] N.M. Bujurke, S.C. Shiralashetti, C.S Salimath, An Application of Single-term Haar Wavelet Series in the Solution of Nonlinear Oscillator Equations, J. Comput. Appl. Math. 227 (2009) 234-244.

[8] J.F. Carinena et al., Related operators and exact solutions of Schrodinger equations, Int. J. Mod. Phys. A. 13 (1998) 4913-4929.

[9] C.F. Chen, C.H. Hsiao, Haar wavelet method for solving lumped and distributed-parameter systems, IEEE Proc. Pt. D. 144 (1) (1997) 87-94.

[10] S. Dhawan, S. Arora, S. Kumar, Wavelet based numerical scheme for differential equations, Int. J. of Differential Equations and Applications. 12(2) (2013) 85-94.

[11] K. Diethelm et al., Pitfalls in fast numerical solvers for fractional differential equations, J. Comput. Appl. Math. 186 (2006) 482-503. 
[12] M.A. El-Tawil, A.A. Bahnasawi, A. Abdel-Naby, Solving Riccati differential equation using Adomians decomposition method, Appl. Math. Comput. 157 (2004) 503-514.

[13] F. Geng, Y. Lin, M. Cui, A piecewise variational iteration method for Riccati differential equations, Comput. Math. Appl. 58 (2009) 2518-2522.

[14] R. Gorenflo, Afterthoughts on interpretation of fractional derivatives and integrals, in: P. Rusev, I. Dimovski, V. Kiryakova (Eds.), Transform Methods and Special Functions, Varna 96, Bulgarian Academy of Sciences, Institute of Mathematics and Informatics, Sofia, 1998, pp. 589-591.

[15] S. Islam, I. Aziz, B. Sarler, The numerical solution of second-order boundary-value problems by collocation method with the Haar wavelets, Math. Comput. Model. 52 (2010) 1577-1590.

[16] A. Kilicman, Z. A.A.A. Zhour, Kronecker operational metrics for fractional calculus and some applications, Appl. Math. Comput. 187 (2007) 250-265.

[17] U. Lepik, Numerical solution of differential equations using Haar wavelets, Math. Comput. Simul. 68 (2005) 127-143.

[18] U. Lepik, Application of the Haar wavelet transform to solving integral and differential Equations, Proc. Estonian Acad Sci. Phys. Math. 56(1) (2007) 28-46.

[19] Y. Li, W. Zhao, Haar wavelet operational matrix of fractional order integration and its applications in solving the fractional order differential equations, Appl. Math. Comput. 216 (2010) 2276-2285.

[20] S. Momani, N. Shawagfeh, Decomposition method for solving fractional Riccati differential equations, Appl. Math. Comput. 182 (2006) 1083-1092.

[21] W.T. Reid, Riccati Differential Equations, Academic Press, NewYork, 1972.

[22] M.R. Scott, Invariant Imbedding and its Applications to Ordinary Differential Equations, Addison-Wesley, 1973.

[23] Z. Shi, Y. Cao, Application of Haar wavelet method to eigenvalue problems of high order differential equations, Appl. Math. Model. 36 (2012) (9) 4020-4026.

[24] B.Q. Tang, X.F. Li, A new method for determining the solution of Riccati differential equations, Appl. Math. Comput. 194 (2007) 431-440. 